\title{
University studies after the pandemic. Challenges and solutions
}

\author{
Svetlana Akhmetova*, Larisa Nevskaya, and Irena Esaulova \\ Perm National Research Polytechnic University, Perm, Russian Federation
}

\begin{abstract}
The transition of higher education institutions to a distance format during the pandemic has become the most discussed topic in the teaching community. As a result of the pandemic, all Russian universities found themselves in a situation where the educational process and its management were switched to a remote format all at once. This transition has accelerated the development of the digital infrastructure of universities and the inclusion of all faculty and students in the online educational environment. The Coronavirus pandemic has highlighted that, following a gradual return to a traditional form of learning, the learning strategy and resources used must change. The new environment will require new skills from teachers and students and thus changes in learning technology. New learning areas include digital tools skills, team (group) working skills in a digital environment, and skills for sharing synchronous and asynchronous formats. The article presents an analysis of the implementation of new approaches to learning during the pandemic and the prerequisites for their use after returning to the traditional form of the learning process. An analysis of attitudes of teachers and students of Perm National Research Polytechnic University towards using new tools and technologies for sustainable development of the educational process is presented. Based on the analysis, barriers to implementing the new approach are identified, and recommendations for overcoming them are offered.
\end{abstract}

\section{Introduction}

Technological change in the world is happening faster and faster, and not always predictably. The VUCA model describes these changes, meaning volatile, uncertain, complex, and ambiguous. In the education system, this means that we don't know if our graduates will be in demand and if the profession they will graduate from will survive. This is the result of rapid technological development and digital transformation in all areas of life.

The challenges of the new world model in education relate to the constant development of digital tools and learning technologies, the changing generation of students, the changing labor market, and new requirements for competencies and positions. The processes of introducing new tools and technologies launched during the pandemic changed the traditional balance of educational formats and approaches. Many universities have started to actively use platforms to implement a synchronous format of education: web conferences, webinars,

\footnotetext{
${ }^{*}$ Corresponding author: sgahmetova@gmail.com
} 
online training. The use of learning portals to host e-learning courses of disciplines has become more active. But what happened during the pandemic is not a new approach to learning, just the migration of face-to-face classes to an online environment.

The new approach to learning should be based on modern educational technologies (Educational technologies, EduTech), which are a set of tools, technologies, and approaches used in education. The following components of EduTech are distinguished: approaches to learning organization; technologies to increase motivation and involvement in learning; synchronous and asynchronous learning formats; tools to work on the content and its implementation in the educational process.

Approaches to the organization of training

The practice-oriented approach is widely covered in the works of Russian and foreign scientists $[1,2,3]$. Learning through experience allows realizing the needs of modern students in acquiring professional skills. In this regard, the need to develop a mechanism of interaction between universities and potential employers is of particular relevance. At the same time, special attention should be paid to the involvement of employers in the process of students' practical skills acquisition and the process of graduates' employment [4].

A blended approach is one of the elements of the digital transformation of education. This approach combines traditional (lectures, seminars) and online learning technologies for more effective implementation of the learning process and students' acquisition of digital and communication skills. The successful implementation of blended learning format requires appropriate facilities (equipment, software); a communicative environment for the interaction of students with each other and the teacher; the possibility of greater freedom in the choice of teaching methods. The synchronous blended learning format is based on video conferencing to implement lecture classes, online training, and group work on projects. The asynchronous format uses LMS (Learning Management System). The LMS is the primary tool for implementing a mixed format. Such educational platforms are now available at most Russian universities, but not all of them use them effectively.

Social Learning. Social learning allows the implementation of informal exchange of information between students and the instructor by creating a social network platform. Modern social media provides a wide range of opportunities for publishing learning materials and for communicating with students. The experience of using social networks by students to communicate can also be used in the educational process, as evidenced by the active discussion of these issues in the teaching community [5].

One important component of EduTech is technology to increase motivation and engagement in the learning process. A blended learning approach provides an opportunity to use effective techniques for this purpose, such as the Flipped Classroom model, simulations, role-playing, and gamification [6].

Successful implementation of these approaches requires tools that can support the elearning process. In the educational technology marketplace, many educational technologies and applications were overlooked by university educators until the urgent move of universities to an online environment. During the acute period of the pandemic, all training content was moved to online broadcasting. The most popular tool for organizing the learning process was Zoom video conferencing service. The pandemic experience has enabled universities to improve the infrastructure and environment for developing the digital competencies of faculty and students. Some teachers have started to realize the necessity of using online formats in the teaching process and developing teaching and learning materials in electronic form. But the most important thing is not only the development of educational materials in electronic form but the transition from the traditional model of the educational process to new models based on the use of modern educational technologies. 


\section{Research methodology}

The study is based on the authors' study of available sources of Russian and foreign literature. The results of sociological studies conducted by Russian and foreign scientists on training results during the quarantine period were also studied. The work with sources was based on the application of comparative analysis and synthesis methods.

In conducting the study, the authors solved the following tasks:

What approaches to learning during the pandemic have been most effective? In the transition to the traditional form of the learning process, these of these are necessary for the sustainable development of the learning process. What are the barriers to the transition to the new format of learning typical for students and teachers?

The research base is the Humanities Department of Perm National Research Polytechnic University (PNRPU). A total of 280 students and 120 faculty members participated in the study.

\section{Results of the study}

The Faculty of Humanities of Perm National Research Polytechnic University (PNRPU) uses Moodle portal version 3.2 as a platform for implementing blended learning. The results of a study on the use of portal capabilities in the educational process conducted by the authors in 2018 showed that only one department of the faculty out of 9 used the portal capabilities to the fullest extent [7]. This allowed faculty and students in this department to transition relatively painlessly to a remote format during the pandemic.

A new study conducted by the authors among liberal arts students found little change in faculty use of the portal during the pandemic. Only a small fraction of teachers from other departments have taken advantage of the portal to download teaching materials. Rather actively, some faculty members started to use video conferencing for lecture classes. However, the most widespread forms of lectures and practical classes proved to be sending the text of lectures, presentations, assignments, seminar plans to e-mail followed by sending answers to the instructor's questions. Approximately the same conclusions were obtained from the results of research in other Russian universities $[8,9,10]$. All this shows that some of our faculty members lack the necessary digital competencies and understanding of the importance of transitioning to new educational models in modern conditions.

The study of the reasons for this attitude of teachers to the use of educational tools, conducted by the authors, revealed two groups of barriers: distrust of the distance format and weak digital competencies of teachers.

The distrust of the distance format is related to the lack of sufficient knowledge of the capabilities of the training platforms. For example, to avoid dishonest behavior of students when performing tasks, tests, you can use the restrictions on different parameters - time, groups, a particular student; to form reports on the activity of a particular student. Interaction with students is ensured through group and individual messaging both within the learning platforms and social media.

A more challenging barrier is the weak digital competencies of teachers. Currently, there is no single list of digital competencies. Their list is most fully presented in S. Carretero, R. Vuorikari, Y. Punie [11]. For teachers, the most important areas of digital competence are (digital fluency) digital literacy: - the ability to find and critically comprehend digital content; communication and collaboration in the digital environment; the ability to create digital content in different formats and the ability to protect personal data and ensure security and privacy $[12,13]$. The study has shown that many faculty members do not fully possess these competencies. The main reasons for reluctance to develop digital competencies are, in their 
opinion, high study load and lack of motivation. These reasons are also indicated by the results of studies by other authors $[14,15]$.

\section{Discussion}

The experience of forced distance learning during the pandemic showed the possibility and expediency of implementing a part of the traditional higher education program in the online format outside the classroom. The need to consider this experience when returning to the traditional learning process is actively discussed in the teaching community [16].

During the pandemic, learning materials were transferred online without regard to digital opportunities, reducing the quality of learning. This was due to insufficient digital competence of teachers and lack of experience in working with new educational technologies. According to many experts, a new learning model is needed that combines traditional communication and learning activities with online learning and interaction in an online environment.

\section{Conclusion}

Digital transformation is changing all spheres of human life: new professions, new educational technologies, forms, and methods of the learning process are appearing. One of Perm National Research Polytechnic University's (PNRPU) competitiveness enhancement programs is developing distance learning and integrating it into the traditional educational process. To implement the program, teachers need to be appropriately motivated. Unfortunately, PNRPU has virtually no incentives to develop digital competencies and develop new learning models. The assessment of a teacher's personal effectiveness is more often than not formal; the teacher's key performance indicators do not reflect their potential and do not encourage development.

One solution to the problem of teacher motivation could be a change in teacher performance indicators. Individual teacher rating should additionally include the following components: the creation of e-course with the publication of learning and control resources on the discipline; maintenance of e-course to support students' independent work; creation of platform in social network for informal interaction with students. In our opinion, this should influence the active use of educational technologies in the educational process and the application of new teaching models.

On the part of the university management, it is necessary to provide technical support for new training models to support teachers in creating e-courses.

\section{References}

1. I.V. Vyatkina, Pedagogical conditions for the professional education of future specialists in a technical university (2017)

2. E.M. Post, Studien zur Verknüpfung von Erfahrung, Reflexion und Transfer (2010)

3. S. Pietsch, Praxisnahe Fallarbeit -ein Beitrag zur Professionalisierung in der universitären (2010)

4. D.K. Sabirova, Management 2(4), 80 (2014)

5. S. Buturlin, A.P. Ozhegova, N.V. Lomovtseva, Materials of the International Scientific and Practical Conference "Continuing Education: Theory and Practice of Implementation", 28 (2018)

6. N.I. Isupova, T.N. Suvorova, Prospects for Science and Education 5(41), 412 (2019) 
7. S.G. Akhmetova, L.V. Nevskaya, Law and Education 6, 25 (2019)

8. G.V. Abrahamyan, G.R. Katasonova, Modern problems of science and education, 3 (2020)

9. I.R. Gafurov, G.I. Ibragimov, A.M. Kalimullin, T.B. Alishev, Higher education in Russia 29(10), 101 (2020)

10. I.A. Aleshkovsky, A.T. Gasparishvili, O. V. Krukhmaleva, N.P. Narbut, N.E. Savina, Higher education in Russia 29(10), 86 (2020)

11. S. Carretero, DigComp 2.1: The Digital Competence Framework for Citizens with eight proficiency levels and examples of use (2017)

12. Teaching Digital Skills: Global Challenges and Best Practices, Analytical Report for the III International Conference "More than Learning: How to Develop Digital Skills", 122 (2018)

13. S. G. Akhmetova, L. V. Nevskaya, IDIMT-2019, 143 (2019)

14. E. F. Zeer, Pedagogical Education in Russia 3, 26 (2020)

15. E. Yu. Grabko, T.A. Avalanche, Modern problems of science and education, 2 (2014)

16. Lessons from the stress test. Universities in a pandemic and after it, The Quality of Education Journal 2, 40 